\title{
Determination of L-Ascorbic Acid by a Flow Injection Analysis with Copper(II)-Mediated Electrochemical Detection
}

\author{
Akira Sano, Tomoko Kuwayama, Mayuuko Furukawa, \\ Shoji Takitani and Hiroshi Nakamura ${ }^{\dagger}$ \\ Faculty of Pharmaceutical Sciences, Science University of Tokyo, \\ Ichigaya-funagawara-machi, Shinjuku, Tokyo 162, Japan
}

\begin{abstract}
An electrochemical method has been developed for the determination of L-ascorbic acid (AsA) by a flow injection analysis. The method is based on a reaction of AsA with copper(II) at $\mathrm{pH} 5.0$ to form a readily oxidizable species, followed by electrochemical detection at an applied potential of $+20 \mathrm{mV} v \mathrm{vs}$. Ag/AgCl. Under the optimum conditions a linear calibration curve was obtained for AsA over the concentration range from 0.1 to $20 \mu \mathrm{M}$ with a sample volume of $20 \mu \mathrm{l}$. The relative standard deviation of the peak height for $10 \mu \mathrm{M}$ AsA was $1.0 \%(n=10)$. The method was successfully applied to the determination of AsA in fresh fruit juices and soft drinks. The obtained results are in good agreement with those obtained by high-performance liquid chromatography $(r=0.994)$.
\end{abstract}

Keywords L-Ascorbic acid, flow injection analysis, copper(II)-mediated electrochemical detection, ascorbic acid radical, fruit juices, soft drinks

Since L-ascorbic acid (AsA) plays important roles in living bodies and primates lack the ability to biosynthesize AsA, a number of methods have been reported for the determination of AsA in both foods and biological fluids. ${ }^{1-3}$ Of these, methods using flow injection analysis (FIA) ${ }^{4-13}$ or high-performance liquid chromatography (HPLC) with an electrochemical detector (ECD) ${ }^{1-3,14}$ have been widely used. The use of FIA generally offers a rapid and economical method that is suitable for routine analysęs. In the FIA of AsA, however, the direct application of ECD, as used in HPLC, has not yet been reported, probably due to the limited selectivity of ECD toward complexed matrices of biological samples.

We have recently found that AsA is readily oxidized on a glassy carbon electrode at an extremely low applied potential $(\approx+20 \mathrm{mV} v s . \mathrm{Ag} / \mathrm{AgCl})$ in the presence of copper(II) in weakly acidic media. Although it is well known that the oxidation of AsA is accelerated by the presence of catalytic metals, such as copper(II) and iron(III) ${ }^{15,16}$, no FIA-ECD method utilizing this phenomenon has been reported.

In this paper, we describe an FIA system devised for the sensitive and selective determination of AsA based on our above-mentioned finding. The proposed method permitted the analyses of some fruit juices and soft drinks for AsA after a minimum pretreatment, i.e. centrifugation and successive dilution of the samples.

† To whom correspondence should be addressed.

\section{Experimental}

\section{Reagents}

All of the reagents used were of analytical reagent grade, and were used as received. The water used was purified on a Milli RO-Milli $Q$ system (Millipore, Bedford, MA, USA). An acetate buffer (pH 5.0) was prepared by mixing $200 \mathrm{ml}$ of $0.3 \mathrm{M}$ acetic acid and $400 \mathrm{ml}$ of $0.3 \mathrm{M}$ sodium acetate. A copper(II) reagent was prepared by dissolving copper(II) acetate monohydrate (Kanto Chemical, Tokyo, Japan) into the acetate buffer to give a $5 \mathrm{mM}$ solution. Fresh stock solutions $(10 \mathrm{mM})$ of AsA (Kanto Chemical), D-isoascorbic acid (IsA) (Nacalai Tesque, Kyoto, Japan), AsA 2-phosphate (magnesium salt, Wako, Osaka, Japan), AsA 2-sulfate (dipotassium salt, Sigma, St. Louis, MO, USA), Lascorbyl 6-palmitate (Sigma) and L-dehydroascorbic acid (DhA) (Aldrich, Milwaukee, WI, USA) were prepared daily in ice-cold $70 \mathrm{mM}$ acetic acid. The stock solutions were diluted ad libitum with the same solvent before use.

\section{Preparation of beverage samples}

The fruits and soft drinks used were purchased from retail stores in Tokyo. Orange, mandarin orange, lemon and grapefruit juices were prepared by squeezing cut pieces. After centrifugation at $1000 \mathrm{~g}$ for $10 \mathrm{~min}$, aliquots of the supernatants were diluted with $70 \mathrm{mM}$ acetic acid. Soft drinks were diluted with $70 \mathrm{mM}$ acetic acid. These samples were directly subjected to FIA and HPLC analyses. 


\section{FIA system}

A schematic diagram of the FIA system for the determination of AsA is shown in Fig. 1. The carrier solution, $70 \mathrm{mM}$ acetic acid, was pumped at a flow rate of $0.5 \mathrm{ml} / \mathrm{min}$ with a Shimadzu LC-6A pump (Shimadzu, Kyoto, Japan). The sample was injected with a $50 \mu \mathrm{l}$ Hamilton syringe through a Rheodyne injector (Model 7125 ) with a 20 - $\mu$ l sample loop (Rheodyne, Cotati, CA, USA). The copper(II) reagent was added to the carrier stream at a tee connector with a Senshu flow system 3100 pump (Senshu, Tokyo, Japan) at a flow rate of $1.5 \mathrm{ml} / \mathrm{min}$; the mixture was then introduced into a PTFE reaction coil $(0.5 \mathrm{~mm}$ i.d. $\times 60 \mathrm{~cm})$. The electrochemical response was monitored with a Kotaki ECP-1 ECD equipped with a glassy carbon working electrode and an $\mathrm{Ag} / \mathrm{AgCl}$ reference electrode at an applied potential of $+20 \mathrm{mV}$.

\section{HPLC conditions}

The HPLC system comprised a Shimadzu LC-9A pump (Shimadzu), a Rheodyne injector (Model 7125) with a 20- $\mu$ l sample loop and a Cosmosil 5C18-AR column (4.6 mmi.d. $\times 150 \mathrm{~mm}$; particle size, $5 \mu \mathrm{m})$ (Nacalai Tesque) with a LiChrosorb RP-18 guard column (4 mm i.d. $\times 4 \mathrm{~mm}$ ) (E. Merck, Darmstadt, Germany). The columns were maintained at room temperature and eluted by aqueous $0.17 \mathrm{M}$ ammonium phosphate at $\mathrm{pH} 2.8$. The flow rate was $1.0 \mathrm{ml} / \mathrm{min}$. Detection was carried out with a Nihon Seimitsu UV detector (Model NS-310A) set at $254 \mathrm{~nm}$.

\section{Results and Discussion}

\section{Optimization of the FIA system}

In preliminary experiments, a single-channel FIA manifold was tested, in which sample solutions were injected directly into a copper(II) reagent stream. Although this system was simple, it produced negative peaks upon injecting blank or lower concentrations of AsA. To avoid this, another type of FIA manifold, a double-channel system, was employed (Fig. 1), in which sample solutions were injected into a carrier stream that merged downstream with a copper(II) reagent stream. The FIA conditions were optimized by using $10 \mu \mathrm{M}$ AsA and an injection volume of $20 \mu \mathrm{l}$.

\section{Choice of the sample solvent}

Initially, the stability of AsA was tested in various media. AsA solutions $(10 \mu \mathrm{M})$ were prepared with water, $70 \mathrm{mM}$ acetic acid or $50 \mathrm{mM}$ perchloric acid; they were allowed to stand at either room temperature or $0^{\circ} \mathrm{C}$. The residual AsA was determined at an appropriate interval by the FIA system. When prepared with 70 $\mathrm{mM}$ acetic acid and kept at $0^{\circ} \mathrm{C}$, AsA was found to be stable for at least $8 \mathrm{~h}$. However, AsA gradually degraded in water and perchloric acid, even at $0^{\circ} \mathrm{C}$. Metaphosphoric acid, a stabilizer for As $\mathrm{A}^{17}$, could not be

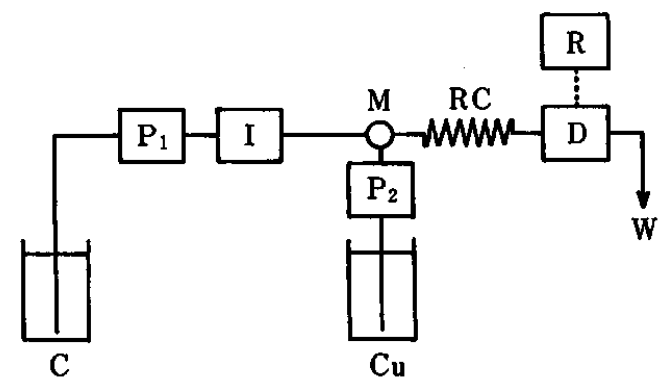

Fig. 1 Schematic diagram of the FIA system. C, carrier; $\mathbf{P}_{1}$ and $P_{2}$, pump; I, injector; $M$, mixing tee; $\mathrm{Cu}$, copper(II) reagent; RC, PTFE reaction coil; D, ECD; R, recorder; W, waste.

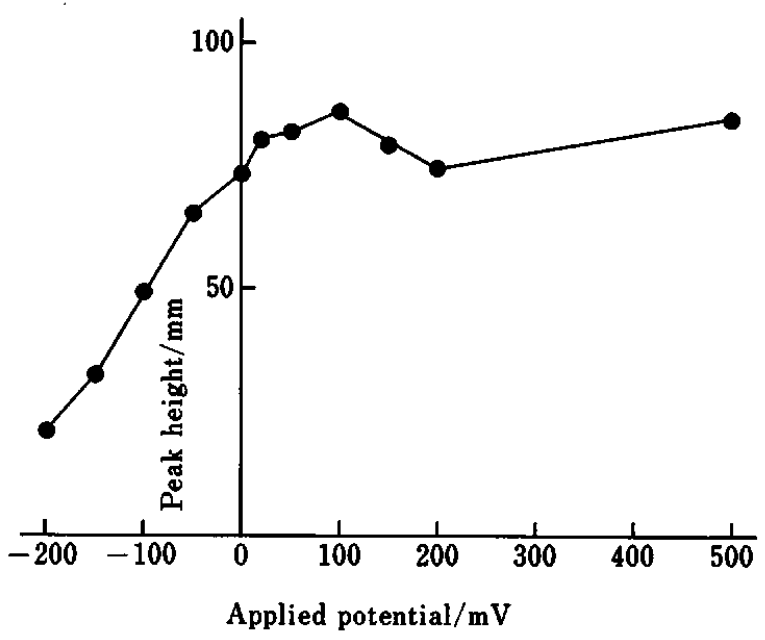

Fig. 2 Effect of the applied potential on the FIA response of AsA. AsA $(10 \mu \mathrm{M})$ in $70 \mathrm{mM}$ acetic acid was tested. The other conditions are the same as those described in the experimental section.

used, because it produced a noisy base line, probably due to its oxidizable property.

Varying concentrations of acetic acid (from 50 to $200 \mathrm{mM}$ ) had almost no effect on the stability or FIA response of AsA. Thus, it was decided to prepare the AsA solution with $70 \mathrm{mM}$ acetic acid. The acidic solution was also used as a carrier in the FIA system.

\section{Applied potential}

The optimum oxidation potential for the FIA detection of AsA was determined using the recommended FIA system (Fig. 1). As shown in Fig. 2, the applied potentials at $+20-150 \mathrm{mV}$ (versus $\mathrm{Ag} / \mathrm{AgCl}$ reference electrode) were found to be optimum. The half-wave potential was estimated to be $-120 \mathrm{mV}$. The potential was therefore set at $+20 \mathrm{mV}$ in order to improve the detection selectivity; the voltage was much lower than that used in conventional ECD methods for AsA (e.g. $\left.+450 \mathrm{mV}^{14}\right)$. 


\section{Effects of a metal ion and buffer}

The FIA response of AsA was markedly influenced by the coexisting metal ion. Copper(II) was chosen as a metal ion because it gave the highest response to AsA; the relative responses induced by nickel(II), cobalt(II) and iron(III) were $4.9,3.7$ and $2.5 \%$ of that by copper(II), respectively. The copper(II) concentration was varied from 1 to $10 \mathrm{mM}$; the highest value with a constant peak height was obtained with a $5-10 \mathrm{mM}$ solution. A $5 \mathrm{mM}$ copper(II) solution was therefore used. For preparing a copper(II) solution, acetate buffer was most suitable compared to other buffer systems, such as phosphate, lactate and citrate, regarding the solubility of copper(II) and the FIA response of AsA. The FIA response of AsA was the highest, and was almost constant in 0.1-0.5 M acetate buffers at pH 5-6. Hence, $0.3 \mathrm{M}$ acetate buffer (pH 5.0) was used to prepare the copper(II) reagent.

\section{Flow rate}

The FIA response of AsA was not very much affected by changes in the flow rates of the carrier and copper(II) reagent over the ranges from 0.5 to $1.0 \mathrm{ml} / \mathrm{min}$ and 0.5 to $2 \mathrm{ml} / \mathrm{min}$, respectively. Therefore, their flow rates were fixed at $0.5 \mathrm{ml} / \mathrm{min}$ and $1.5 \mathrm{ml} / \mathrm{min}$, respectively.

\section{Coil length}

The effect of the length of the reaction coil was examined using $0.25,0.5$ and $1.0 \mathrm{~mm}$ i.d. of PTFE tubing (Fig. 3). The maximum peak height was obtained with a $60 \mathrm{~cm}$ coil of $0.25 \mathrm{~mm}$ i.d. tube. However, it was observed that the base-line noise increased upon decreasing both the inner diameter and the coil length. Therefore, a $60 \mathrm{~cm}$ coil of $0.5 \mathrm{~mm}$ i.d. (residence time, $3.5 \mathrm{~s})$ was used while sacrificing the response $(83 \%$ to that of the maximum).

\section{FIA responses of AsA-related compounds and other foreign substances}

Table 1 shows the relative FIA responses of AsA and some structurally related compounds. AsA, Is A and L-ascorbyl 6-palmitate gave a similar level of response. However, esterified AsA at C-2 and DhA gave practically no response. In the FIA system it may be concluded that although the intact enediol structure at $\mathrm{C}-2$ and C-3 in AsA is essential to give a positive response, substitution of the hydroxy group at C-6 does not lower the response very much.

The following substances $(10 \mu \mathrm{M})$ did not show any FIA response under the recommended conditions, and, therefore, did not interfere with the determination of AsA $(10 \mu \mathrm{M})$ : glucose, fructose, sucrose, alanine, arginine, aspartic acid, cystine, glutamic acid, glycine, histidine, isoleucine, leucine, lysine, methionine, phenylalanine, proline, serine, threonine, tryptophan, tyrosine, valine, citric acid, tartaric acid, $\alpha$-ketoglutaric acid, phenylpyruvic acid, indole-3-acetic acid, epinephrine, norepinephrine, dopamine, $p$-hydroxyphenylacetic acid, 3,4-dihydroxyphenylalanine, nicotinamide, pyridoxal-5-

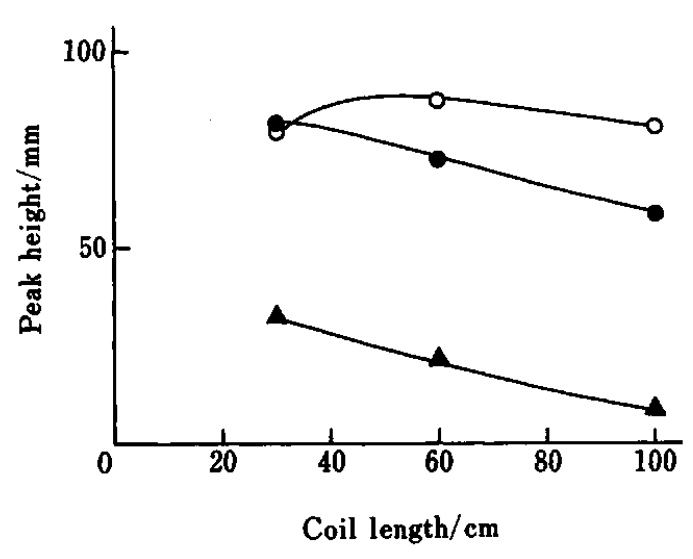

Fig. 3 Effects of the lengths and diameters of the reaction coil on the FIA response of AsA. AsA $(10 \mu \mathrm{M})$ in $70 \mathrm{mM}$ acetic acid was used. Internal diameter of coil: $O, 0.25 \mathrm{~mm}$; $0.5 \mathrm{~mm} ; \Delta, 1.0 \mathrm{~mm}$.

Table 1 FIA responses of AsA and related compounds

\begin{tabular}{|c|c|c|}
\hline Compound & R.P.H. ${ }^{a}$ & \\
\hline AsA $[4 R, 5 S \text {-configuration }]^{\mathrm{b}}$ & 100 & \\
\hline Is $\mathrm{A}[4 R, 5 R \text {-configuration }]^{\mathrm{b}}$ & 94.3 & \\
\hline L-Ascorbyl 6-palmitate ${ }^{b}$ & 50.9 & \\
\hline $\mathrm{DhA}^{\mathrm{c}}$ & 0.3 & Structure of \\
\hline AsA 2-phosphate ${ }^{c}$ & 0.1 & AsA and Is $A$. \\
\hline AsA 2-sulfate ${ }^{c}$ & 0 & \\
\hline
\end{tabular}

a. Relative peak height; AsA was arbitrarily taken as $\mathbf{1 0 0}$.

b. $10 \mu \mathrm{M}$ solution was injected.

c. $100 \mu \mathrm{M}$ solution was injected.

phosphate, $N$-ethylmaleimide, sodium sulfite and potassium thiocyanate. On the other hand, glutathione, cysteine and catechol $(10 \mu \mathrm{M}$ each) showed positive responses corresponding to $16.9,24.1$ and $10.3 \%$ of that given by AsA $(10 \mu \mathrm{M})$, respectively, probably due to their reducing property. However, when equimolar amounts of glutathione, cysteine and catechol were coexistent with AsA $(10 \mu \mathrm{M})$, the recoveries of AsA decreased to 54.2, 60.7 and $90.0 \%$, respectively.

\section{Calibration curve}

A calibration curve for AsA was constructed with the recommended FIA system. The peak heights were proportional to the concentration of AsA in the $0.1-20 \mu \mathrm{M}$ range, and the limit of detection $(S / N=3)$ was $0.05 \mu \mathrm{M}$. The relative standard deviation of the peak height at an AsA concentration of $10 \mu \mathrm{M}$ was $1.0 \%(n=10)$ and the sampling throughput was 30 samples/h (Fig. 4).

The detectability of the present method for AsA is comparable to those based on an electrochemical ${ }^{6}$ 


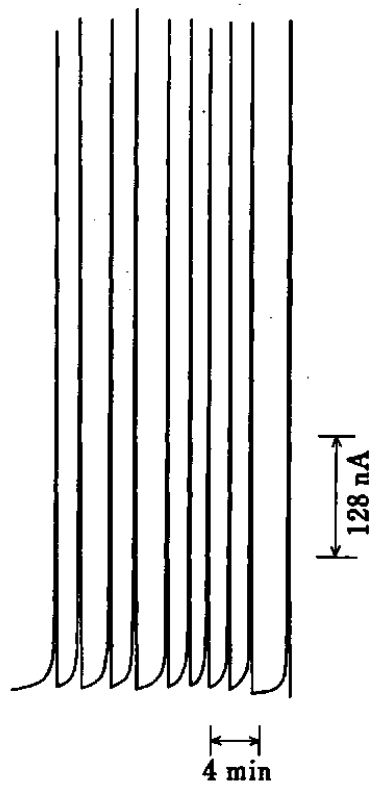

Fig. 4 Typical FIA responses for repeated injection $(20 \mu \mathrm{l})$ of a $10 \mu \mathrm{M}$ authentic AsA solution.

or chemiluminescent reaction ${ }^{7}$, and superior to other FIA methods ${ }^{4,5,8-10,12,13}$, except for the method of Alwarthan ${ }^{11}$, which can detect $10^{-5} \mu \mathrm{M}$ AsA based on a sensitized chemiluminescent reaction.

\section{Determination of AsA in fruit juices and soft drinks}

Prior to applying the proposed method, a recovery test was performed using fresh mandarin orange juice spiked with a known amount of AsA $(50 \mathrm{mg} / 100 \mathrm{ml})$. When the spiked sample was analyzed after centrifugation at $1000 \mathrm{~g}$ for $10 \mathrm{~min}$, followed by dilution of the supernatant with $70 \mathrm{mM}$ acetic acid by a factor of 500 , the recovery of AsA was satisfactory $(96.7 \pm 5.6 \%, n=4)$.

AsA in some fruit juices and drinks was then determined using the recommended FIA system. To check the reliability of the FIA method, the same samples
Table 2 AsA concentrations in fruit juices and soft drinks

\begin{tabular}{llcc}
\hline & Sample & \multicolumn{2}{c}{ AsA $\left(\mathrm{mg} 100 \mathrm{ml}^{-1}\right)^{\mathrm{a}}$} \\
\cline { 3 - 4 } & & FIA & HPLC \\
\hline \multirow{4}{*}{ Fruit } & Orange & 51.2 & 52.1 \\
& Mandarin orange & 26.4 & 29.7 \\
& Lemon & 43.9 & 42.9 \\
& Grapefruit & 37.6 & 39.2 \\
& Grink & 15.9 & 15.4 \\
& Green tea & 11.5 & 11.3 \\
& Oolong tea & 48.2 & 45.3 \\
& Acerola & 9.6 & 11.3 \\
\hline
\end{tabular}

a. Mean of two determinations.

were also analyzed by HPLC according to the method of Shaw and Wilson III ${ }^{18}$, as described in the experimental section. The results are summarized in Table 2. The AsA concentrations obtained by the FIA method $(y)$ agreed well with those obtained by the HPLC method $(x)$ $[y=1.02 x-1.13(r=0.994)]$. The AsA contents in the fresh fruit juices obtained here are also consistent with those listed in an official data book (orange, 40; mandarin orange, 35 ; lemon, 45 ; grapefruit, $40 \mathrm{mg} / 100 \mathrm{~g}$ ). ${ }^{19}$

\section{Electrochemically active species formed from AsA}

Judging from the characteristics of the response behavior of AsA described above and the oxidation reaction mechanism of AsA in the presence of copper(II) (Fig. 5) 3,20 , the ECD-active species is assumed to be copper(I) and/or the AsA radical.

The optimum oxidation potential for detecting AsA $(+20-150 \mathrm{mV})$ was extremely lower than that of AsA itself in the absence of copper(II) (typically $+450 \mathrm{mV}^{14}$ ). This optimal potential suggested the possibility that the FIA response of AsA was based on a reoxidation of copper(I), formed by the reaction shown in Fig. 5, because Noufi et al. ${ }^{21}$ reported that the redox reaction of copper(II)/copper(I) occurred on a carbon-paste elec-

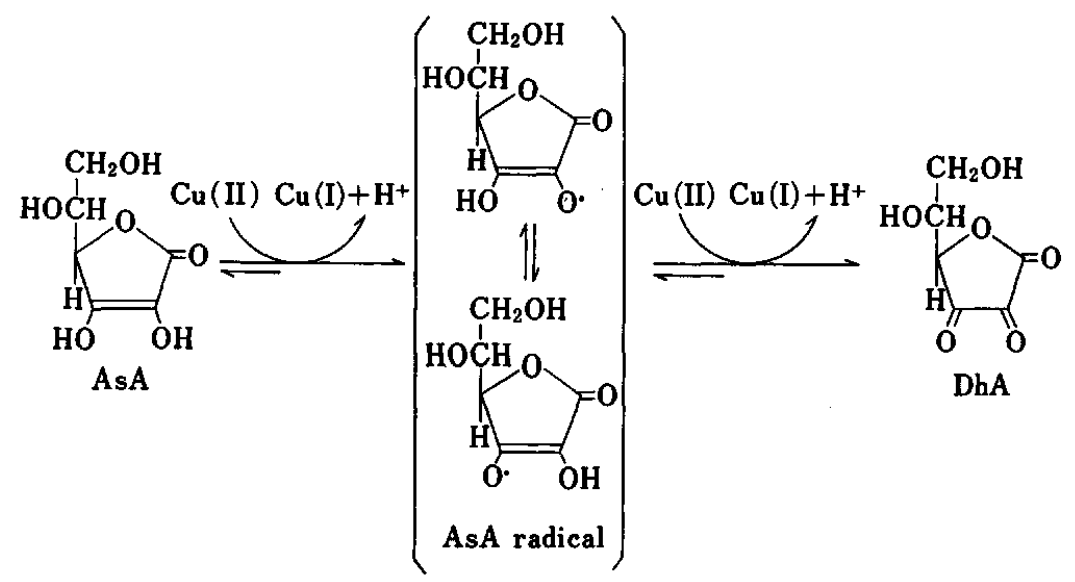

Fig. 5 Oxidation of AsA in the presence of copper(II). 
trode at an applied potential of $+50 \mathrm{mV}$. However, the current for the oxidation of $1 \mathrm{ppm}$ copper(I) (injection volume, $1.2 \mathrm{ml}$ ), at $\mathrm{pH} 6.5$ in an acetate buffer, was reported to be only $65 \mathrm{nA}$, corresponding to $43 \mathrm{nA}$ for a $10 \mu \mathrm{M}$ solution. In contrast, the current given by $10 \mu \mathrm{M}$ AsA in our system was about $700 \mathrm{nA}$ (Fig 4). Furthermore, the curve for the oxidation current of copper(I) versus the applied potential ${ }^{21}$ is somewhat different from that of AsA depicted in Fig. 2. Therefore, the FIA response observed here seems not to be explained in terms of the contribution of copper(I) alone.

On the other hand, a direct detection of the AsA radical is also considered to be feasible, as a second possibility, based on the following viewpoints: 1) The radical has a relatively long lifetime (the half-life of $10^{-7}$ $\mathrm{M}$ AsA radical was estimated to be about $50 \mathrm{~s}$ at $\mathrm{pH} 7.4$ ), compared to other common free radicals $\left(10^{-3}-10^{-9} \mathrm{~s}\right) .^{22}$ In the present FIA-ECD system, the maximum residence time of the radical in the reaction coil is $3.5 \mathrm{~s}$. 2) The self-exchange reaction rate constants for the AsA/AsA radical and AsA radical/DhA were reported to be approximately $10^{6} \mathrm{M}^{-1} \mathrm{~s}^{-1}$ and $2.4 \times 10^{5} \mathrm{M}^{-1} \mathrm{~s}^{-1}$, respectively..$\left.^{23} 3\right)$ The half-wave potential observed here $(-120 \mathrm{mV})$ is consistent with the calculated value for the redox reaction of the AsA radical/DhA at $\mathrm{pH} 6.0$ $(-210 \mathrm{mV}) .^{24}$ However, we cannot determine the chemical species of the ECD-active principal at this stage, since we have no evidence concerning the formation of the AsA radical. Further studies are required to elucidate the mechanism.

In conclusion, the proposed FIA method seems to be useful for the routine analysis of food samples, such as fruit juices and soft drinks, owing to its accuracy and precision as well as good sensitivity, selectivity and simplicity.

\section{References}

1. L. W. Doner, "Trace Analysis", ed. J. F. Lawrence, Vol. 3, p. 113, Academic Press, Orlando, 1984.

2. L. A. Pachla, D. L. Reynolds and P. T. Kissinger, $J$. Assoc. Off. Anal. Chem., 68, 1 (1985).
3. P. W. Washko, R. W. Welch, K. R. Dhariwal, Y. Wang and M. Levine, Anal. Biochem., 204, 1 (1992).

4. S. Uchiyama, Y. Tofuku and S. Suzuki, Anal. Chim. Acta, 208, 291 (1988).

5. M. A. Abdalla and H. M. Al-Swaidan, Analyst [London], 114, 583 (1989).

6. G. M. Greenway and P. Ongomo, Analyst [London], 115, 1297 (1990).

7. J. M. Kim, Y. Huang and R. D. Schmid, Anal. Lett., 23, 2273 (1990).

8. K. K. Verma, A. Jain, A. Verma and A. Chaurasia, Analyst [London], 116, 641 (1991).

9. D. T. Burns, N. Chimpalee, D. Chimpalee and S. Rattanariderom, Anal. Chim. Acta, 243, 187 (1991).

10. Y.-S. Fung and S.-Y. Mo, Anal. Chim. Acta, 261, 375 (1992).

11. A. A. Alwarthan, Analyst [London], 118, 639 (1993).

12. S. M. Sultan, A. M. Abdennabi and F. E. O. Suliman, Talanta, 41, 125 (1994).

13. M. Goto, K. Akabori and S. Maeda, Bunseki Kagaku, 43, 505 (1994).

14. L. A. Pachla and P. T. Kissinger, "Methods in Enzymology", ed. D. B. McCormick and L. D. Wright, Vol. 62, p. 15, Academic Press, New York, 1979.

15. G. R. Buettner, Free Rad. Res. Commun., 1, 349 (1986).

16. G. R. Buettner, J. Biochem. Biophys. Methods, 16, 27 (1988).

17. D. W. Bradley, G. Emery and J. E. Maynard, Clin. Chim. Acta, 4, 47 (1973).

18. P. E. Shaw and C. W. Wilson, III, J. Agric. Food Chem., 30, 394 (1982).

19. The Science and Technology Agency, "Standard Tables of Food Composition in Japan", 4th ed., 1983.

20. K. Aihara, Y. Urano, T. Higuchi and M. Hirobe, J. Chem. Soc. Perkin Trans. 2, 1993, 2165.

21. M. Noufi, Ch. Yarnitzky and M. Ariel, Anal. Chim. Acta, 228, 117 (1990).

22. G. R. Buettner and B. A. Jurkiewicz, Free Rad. Biol. Med., 14, 49 (1993).

23. N. H. Williams and J. K. Yandell, Aust. J. Chem., 35, 1133 (1982).

24. T. Iyanagi, I. Yamazaki and K. F. Anan, Biochim. Biophys. Acta, 806, 255 (1985).

(Received February 16, 1995)

(Accepted March 31, 1995) 